\title{
Strengthening the Online Auction Culture of the Philippines
}

\author{
Martiniano Jake P. Neri III \\ CUREXO-IDS, Capitol University, \\ Cagayan de Oro City, Philippines \\ docachmed@gmail.com
}

\section{Arnel Bangis, Theresa Budlong, Jade Clado, Irish Christine Ebot, Analy Fransisco and Minstrel Ignacio College of Business Administration, Capitol University, Cagayan de Oro City, Philippines}

\author{
arnel_bangis@yahoo.com, budlongthesa@yahoo.com, \\ preciousjade17@yahoo.com, mcy_musicministry@yahoo.com, \\ analygales@yahoo.com, minstrel_137@yahoo.com
}

\begin{abstract}
This paper examines global patterns in pre-identified attributes that contribute to the success or behavior of e-auctions in certain region-based websites associated with a recognized web brand in web-based bidding. It used 18 countries data on e-auction characteristics that focus on context, input, process, output and outcomes with the purpose as guidance to obtain and strengthen policybased recommendation in the review and accordance of the e-Commerce Act of 2000. 18 variables were used as multivariate inputs in a cluster analysis algorithm aimed to cluster countries in 18 x 18 similarity matrix utilizing a hierarchical clustering method. Information capturing variable descriptions was obtained from standard reports and a web-based observation in a definite period of time. Results revealed that buyer satisfaction varied strongly with high and low ranking countries in terms of Context (Network Readiness Index, Human Development Index and Level of Development), Input (Internet speed, Site Language, Trading Scope, Membership and Merchant type), Process (Checkout, Delivery and Payment methods), Output (Taxation, Buyer protection, Product Exchange Options and Merchandise Returns) and Outcome (Positive feedback score and Seller ratings). On the basis of the cluster analysis performed and validation of theoretical discovery, Policy allusions are given as recommendations to enhance, improve and consolidate the e-commerce Act of the Philippines to augment its contribution to national development.
\end{abstract}

Material published as part of this publication, either on-line or in print, is copyrighted by the Informing Science Institute. Permission to make digital or paper copy of part or all of these works for personal or classroom use is granted without fee provided that the copies are not made or distributed for profit or commercial advantage AND that copies 1) bear this notice in full and 2) give the full citation on the first page. It is permissible to abstract these works so long as credit is given. To copy in all other cases or to republish or to post on a server or to redistribute to lists requires specific permission and payment of a fee. Contact Publisher@InformingScience.org to request redistribution permission.
Keywords: e-auction, e-commerce, policy, cluster analysis, hierarchical method

\section{Introduction}

The role of Information Technology in the society is plainly visible in the developments contributing to the ease of communication, basically decongesting the information highway by increasing bandwidth and speed, along with real time communication activities between 
individuals separated around the globe. The advent of the internet allowed the creation of virtual communities (Kluge \& Riley, 2008) and identities, allowing personas to communicate in digital form, hold virtual sessions in the academe and socialize (Coll, Dell Vecchio, Metzer, Scalise, Arrechederra, \& Fariña, 2004). Several of these functions include online transactions over a secure server and the exchange of goods and services with individuals who did not even meet physically. These developments are readily available to countries all over the world with access to the World Wide Web. Commercial contexts in Information Technology led to the continued developments of third party applications that provide the buyer, the marketplace and the seller virtual identities, removing the need of the middleman; it also steeply cut the cost of the selling expenses. The term Electronic Commerce (e-commerce) was then the standard definition of business transactions done within the realm of the digital interface. Over time, any transaction which is commercial in nature, to name a few, developing, marketing, selling, delivering, servicing and paying for products and services done in the Internet or a computer system, was included in the definition. There are even academic endeavors and specific discipline in the conduct of successful e-commerce pursuit (Sicilia, 2005). Ecommerce officially took flight with Michael Aldrich inventing online shopping in 1979 (Tkacz \& Kapczynski, 2009, p. 255).

The conduct of commerce operationally done this way became a wildfire sensation, spurring and drawing on innovations from users that identified problems and other individuals providing solutions. Electronic funds transfer became the safest way to move money from one hand to another (Turban et al., 2008); supply chain management made sure that the product development cycle never missed a deadline or production date (Harland, 1996); Internet marketing cut the cost of advertising and increased scope and range (Gurevych, 2007); online transaction processing secured business agreements in multiple layers of encryption and security (Richardson, 2008), electronic data interchange (EDI) sped up information exchanges with companies operating in an international level (Kantor \& Burrows, 1996), at which its back office is in a location half the globe away from its processing plant; inventory management systems and automated data collection systems that perform according to specific design and goals.

Modern e-commerce typically uses the World Wide Web (www) in at least one point, whether it is at the beginning, within, or at the end of the transaction's life-cycle. Several add-ons of the technology contribute to related services that encompass a wider range of use, such as e-mail for encoded communication, mobile devices for voice and SMS messaging and other business-related technologies as well. Businesses that adapt to this technology are descriptive of the term "brick and click"; business are formed physically and at the same time, adapt an online identity for online purposes. The once conservative group of businesses initially refused to join the web bandwagon, fearing that this would conflict with their physical (offline) customers, and was skeptical about the idea as it could complicate their identities even to their own physical stores. In order to compete with "pure-click" companies (companies that launched a website without existing as a firm), the brick and click group vied also for new developments such as total customer satisfaction and after sales customer service. Electronic Business to Business (B2B) was utilized to achieve optimal results (Ferbar, 2004).

In the Philippines, the Ecommerce Act of 2000 (also known as the Republic Act 8792 of the Republic of the Philippines) (Chan \& Robles, 1998-2006) recognizes the role of Information and Communications Technology (ICT) as a strong component in building the country. It stipulated the need to create an Information Technology (IT) friendly environment which supports and ensures the availability, diversity and affordability of ICT products and services and recognizes the private sector responsibility in contributing investments and services in ICT. This law paved a fertile ground for Filipino individuals with inclination in technology to venture into online businesses and services. 
The Filipino online community is closely knit in terms of social networking and communications as the Philippines is one of the most developed SMS and web-based communication hub in South-East Asia. There are over 72 million subscribers (Wood, 2010) of the short messaging system (SMS) as of 2009, and roughly around 1.39 billion text messages sent every day (AHN Media Corporation, 2006-2009). The community also continues to evolve to other media streams to pass information around, while also engaging into a business-like entity as SMS operators offer unlimited sending capacity over a definite period to time. On the other hand, consumer response also triggered a new onslaught of problems (Jøsang et al., 2007) ranging from unsolicited messaging to personal information phishing to unfair commercial practices with intention to commit fraud.

The study focused on business to business (B2B) transactions and identified the online auction culture of Filipinos with transactions in the web. Specifically, it defined the concept of online auctioning as a way to transact or sell a product. Identified websites with auctioning capability and capacity were subjected to observation on its transaction details, building trust between the buyer and seller, building good relationship between the courier to the company, customer feedback, mode of payment and post-sale services.

The study attempted to provide a descriptive picture of the current state of electronic commerce/online auction of the Philippines and the rest of the world as observed from multiple business entities presently and readily available for immediate access. Specifically, it attempted to:

- Compare information about current trends in product delivery, payment schemes and buyer protection

- Provide information about the current e-auction culture in the Philippines and how it matches up to the global platform

- Provide theories based on behavior observed from multi-tier level economies

- Provide recommendation based on theories on how to improve the e-commerce culture through legislative influence

The study was designed to be useful be useful for individuals seeking web-based business opportunities with the intention to educate such with the behavior and consideration prior to opening a business online. It will also be useful for policy makers in aid of legislation to identify fraud practices for the protection of the greater public. Lastly, it also intends to strengthen the e-commerce Act of 2000 as it will define new terms on how the proper conduct of business is to be carried out in the web.

\section{Methodology}

The study revolved basically in descriptive and correlational analysis of business entities, whether it is an online transaction or a physical exchange of merchandise after monetary consideration was considered. On a regular transaction, the seller expresses little or no hesitation in terms of security of exchange of goods (since the buyer can see the seller's goods through an ad while the seller can see and verify the amount of money presented/sent to him after the negotiation and both parties are satisfied with the terms surrounding the transaction), this method can still be a subject of conflict when:

- The quality of the merchandise is not as expected by the buyer

- After sales service is taken for granted

- Buyer intentionally fails to materialize payments due to the technicalities of the means and ways to transact a negotiable instrument/method 
These instances are still available when technological methods are applied to the business parlance. The online action (e-commerce) activity removes the physical representation of parties involved and is characterized by new digital identities with questionable backgrounds and history. As characterized by the human factor of man being a gullible individual, the study of regarding refrigeration repairs where Clepper (1996) indicated the need to protect these individuals through consumer education. It is through buyer and seller education that lesser problems may occur surrounding the transaction itself, subjecting that the terms presented by both parties satisfy the intention of barter, selling or trade. Countries all over the world have e-commerce cultures and practices worth emulating with end-results determined to be a win-win scenario. This study utilized this perception on positive attributes applicable with the Philippine online selling/buying preferences.

The researchers initially utilized the internet and web resources using secondary information from mother/main websites. An initial assessment has been conducted to determine the volume of ecommerce activity in global major sites, namely:
- E-bay Global (US)
- E-bay Sweden
- E-bay Norway
- E-bay India
- E-bay New Zealand
- E-bay UK

- E-bay Ireland

- E-bay France

- E-bay Spain

- E-bay Australia

- E-bay Malaysia

- E-bay Poland
- E-bay Vietnam

- E-bay Canada

- E-bay Singapore

- E-bay Philippines

- E-bay Portugal

- E-bay Switzerland

The study looked into various factors that affect the quality of service and buying/selling practices. It will also propose to use multivariate analysis from 5 factors namely: Context factor, Input factor, Process factor, Output factor and the Outcome factor. Each of these factors is predetermined as such the information of measure is available in the aforementioned countries. A country will be eliminated if the variables defining the factor are incomplete in the data gathering phase.

To gather the information needed in the survey, the study anchored on the principle that variances in the context, inputs, processes, output and outcome of the e-commerce behavior from different countries are attributed to varying web culture, buying attitudes and online standards. Such perspectives are motivated by economic, social or political pursuits in whittling the shared objectives of its players. This utilized the descriptive analytical method, encompassing the method of cluster analysis (Johnson et al., 1992; Tyron, 1939). This, in mind, is used develop taxonomies from observed exploratory data, associating the attributes or characteristics of objects if they belong to the same group or not. Padua (2007) stated that this method can be utilized to discover structures with minimal explanation or interpretation. To lump smaller groups into larger sets, weighted averages (or centroids) of groups were used as basis. In summary, only 18 (eighteen) countries (from the pre-identified of 58, then trimmed to 37 with local ebay) were used in the comparison (determined by its ability to complete the dataset in an observation lasting 30 days). Specific procedures in the conduct of the data gathering are described below.

The Context factors categorized each country according to its rank in the Network Readiness Index (NRI) published by Global Information Technology Report of 2011, which looked into the environment for ICT offered by a given country or community (Market, political and regulatory, infrastructure environment), the readiness of the community's key stakeholders (individuals, businesses, and governments) to use ICT, and finally the usage of ICT amongst these stakeholders (Dutta \& Mia, 2011). Other variables consid- 
ered included the Human Development Index (HDI) and the Level of Development for each of the eighteen countries.

The Input factors considered the average national Internet Service Provider (ISP) speed in megabytes per second (mbps), languages used and translation availability in trading sites, status of the Items (whether the item is locally or internationally traded), length of membership to the auction site, as well as trader attributes (whether the trader has an electronic store or not).

The process factors looked into three variables. First, it recorded the trending number of transaction methods or ways to initiate barter or trade. Second, it also measured the number of delivery methods available to the buyer that makes the purchase feasible, and third, it looked of the payment mechanisms available inside and outside the auction site.

The Output factors looked into value-added services relating to the purchase such as the presence or absence of taxes, warranties, exchange/return options and buyer protection.

The Outcome factors measured the positive feedbacks accumulated by the trader, his feedback score in percentage as a manifestation of the level of trust given as a feedback by each successful transaction.

The data gathering procedure also involved the categorizing of secondary data from 18 countries are divided into three groups in terms of their indices in the variables, and divided into three categories, the lower 'third', mid 'third' and the upper 'third'. These are readily available from verified sources (e.g., Annual GIT report, HDI from UNESCO, etc.). Other data is derived from direct observation of the Ad; nominal data for the existence of absence of a service, relevant data for scaled information (e.g., internet speed).

The factors and their variables are further explained as follows:

1. Context factors

a. Network Readiness Index - indexed by the Global Information Technology Report of 2010-2011

b. Human Development Index

2. Input factors

c. Level of Development

a. Internet Speed

b. Language Used in site

c. Item Status

d. Membership

e. Product Type

3. Process factors

a. Transaction Methods available

b. Delivery methods available

c. Payment facilities available

4. Output factors

a. Country-based online Taxation

b. Warranty offered

c. Product Exchange availability

d. Buyer Protection

5. Outcome factors

a. The mean of positive feedback percentage and average seller level 
The buyer and seller 'experience' in an online transaction was the focus of the study. It defined perceived practices regarding the exchange of goods, payment methods and the other attributes achieved by both parties in the entire transaction. The study gathered data from a 30-day random web-based survey of ten product catalogues as listings and information it had with them in the identified popular web-based marketplace.

Lastly, the exchange of payment and merchandise involving monetary transaction and delivering methods are also identified as vital components in the e-commerce industry. A survey of available parcel and transport facilities that can be utilized by buyers to deliver items, as well as money-remittance shops/stalls will be identified for this objective.

Data gathered from these methods will then be summarized and formulated into a feasible and operational payment-to merchandise exchange between sellers and buyers. The said framework will then be made available to policy making bodies for them to formulate public awareness and consumer protection that will strengthen the existing Republic Act of this scope. The country needs to look at factors that were used to measure certain variables that influence the Network Readiness Index, as these are items that greatly influence the participation of its citizen in online business related activities. It currently has very limited options available for online trade, as businessmen still prefer local transaction methods; while topics discussed in the academe about new business trends revolve on theories that could have had significant impact if done with exposures on online-related trading.

\section{Findings of the Study and Interpretations of Results}

The study summarized the characteristics of each country in Table 1:

Table 1: Summary of Country Performances

\begin{tabular}{|c|c|c|c|c|c|c|c|c|c|c|c|c|c|c|c|c|c|}
\hline \multirow{2}{*}{\multicolumn{2}{|c|}{ Country }} & \multicolumn{3}{|c|}{ Context } & \multicolumn{5}{|c|}{ Input } & \multicolumn{3}{|c|}{ Process } & \multicolumn{4}{|c|}{ Output } & \multirow{2}{*}{$\begin{array}{l}\text { Outcome } \\
\text { Rank* }\end{array}$} \\
\hline & & $\frac{\ddot{*}}{\frac{\tilde{r}}{z}}$ & \begin{tabular}{|l}
$\frac{*}{0}$ \\
$\frac{0}{1}$
\end{tabular} & $\begin{array}{l}3 \\
8 \\
0 \\
0 \\
z\end{array}$ & 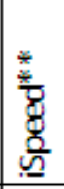 & 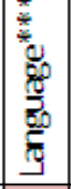 & 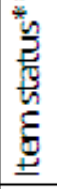 & 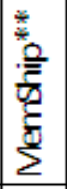 & 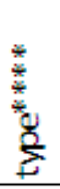 & 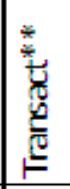 & $\frac{\stackrel{*}{*}}{8}$ & $\sum_{0}^{\frac{\pi}{2}}$ & 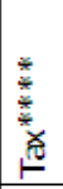 & 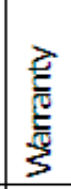 & 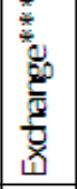 & 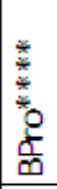 & \\
\hline 1 & Australia & U & 4 & 芒 & - & & O & 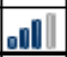 & P & onll| & onll & all| & O & 0 & 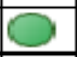 & \% & 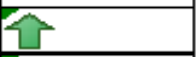 \\
\hline 2 & Canada & $\widehat{U}$ & บ1 & 남 & onll & & 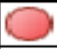 & |nd & 0 & oll & olll\| & onll & 0 & 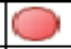 & 0 & & 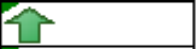 \\
\hline 3 & France & ث & 난 & ث & onll & & 0 & all|| & 0 & olll & all & oll & O & 0 & $O$ & & \\
\hline 4 & India & $\Rightarrow$ & र & र & & & O & onll| & O & ond & olll & & 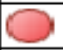 & 0 & 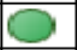 & & 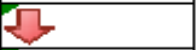 \\
\hline 5 & Ireland & $\widehat{U}$ & 눈 & 芒 & ond & & O & all & 0 & olll & onl & onlll & 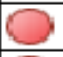 & 0 & $O$ & & 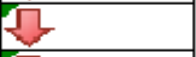 \\
\hline 6 & Malaysia & U & $\Rightarrow$ & $\Rightarrow$ & ond & & $\bigcirc$ & all]\| & O & ond & onl & olll| & O & $\bigcirc$ & 0 & O & 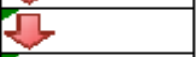 \\
\hline 7 & New Zealanc & U & U & 담 & ond\| & & 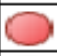 & alll| & $\mathrm{O}$ & olll| & oll & & 0 & $O$ & $\bigcirc$ & & \\
\hline 8 & Norway & U & U & U & olll & & 0 & a & O & ollll| & olll| & olll & O & 0 & O & 0 & $=$ \\
\hline 9 & Philippines & ह & 2 & 2 & ond & & O & all| & O & olln|l| & olll\| & onll| & O & 0 & 0 & O & 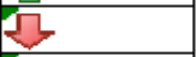 \\
\hline 10 & Poland & $\sqrt{2}$ & U & $\Rightarrow$ & anl|| & & O & |ll| & O & oll & olll| & and & O & $\bigcirc$ & 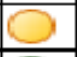 & & 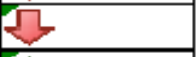 \\
\hline 11 & Portugal & $\Rightarrow$ & U & $\Rightarrow$ & onll| & & $\mathrm{O}$ & all| & O & olll| & olll| & onll| & 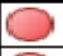 & 0 & $\infty$ & & \\
\hline 12 & Singapore & $\widehat{ن}$ & 4 & 눈 & onll| & & 0 & |n|l| & 0 & onl & $\operatorname{lomll}$ & onll| & $O$ & 0 & $O$ & & \\
\hline 13 & Spain & $\vec{c}$ & U & 它 & oll & & O & إll & O & oll & onll & oll & 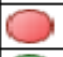 & 0 & 0 & & 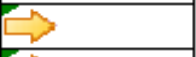 \\
\hline 14 & Sweden & U & 눈 & 눈 & ent & & 0 & all & 0 & olll| & onll & ondll & 0 & 0 & 0 & 0 & \\
\hline 15 & Switzerland & Uे & U & 艺 & onlll & & O & |ll| & 0 & ond & all & onll| & 0 & 0 & 0 & O & 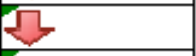 \\
\hline 16 & UK & U & U & U & alll & & O & إل|l| & O & oll|l|| & alll & onll| & $O$ & 0 & $\infty$ & & $>$ \\
\hline 17 & USA & U & U & ث & olll & & O & | & 0 & oll\| & olll & & 0 & 0 & $\bigcirc$ & O & \\
\hline 18 & Vietnam & $\Rightarrow$ & R & 反 & ond & & 0 & 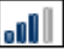 & O & ond & andl & and & 0 & 1 & 0 & $\infty$ & $\Rightarrow$ \\
\hline
\end{tabular}


* $\quad$ All variable values that are icon-rated in arrows indicate high, medium and low in a three-tier percentile performance. This does not indicate that the said country performed low in the actual survey, but only as comparison as one group of 18 countries.

** Signal Bars are in 5-rating scales. The Process Variables are indicative of the number of accessible options provided by the seller. Membership variables are illustrative in number of years.

*** Shading used in Language variable choose between English use (maroon) and Multilingual Language use (teal)

**** Item Status- Red indicate Local Trading, Green for Overseas Trading and Yellow for multi-scope selling coverage

Type - Green indicate Trader (buy and sell), Red indicate Seller only, Yellow indicate shifting trading practices

Output Variables - Reds indicate absence; Greens indicate presence while Yellows indicate selective enforcement

The information gathered from the 30-day trading observation yielded clustered country-specific attributes based on the grouped positive seller ratings and ranks (outcome) unique to the group that they belong with (See Figure 1).

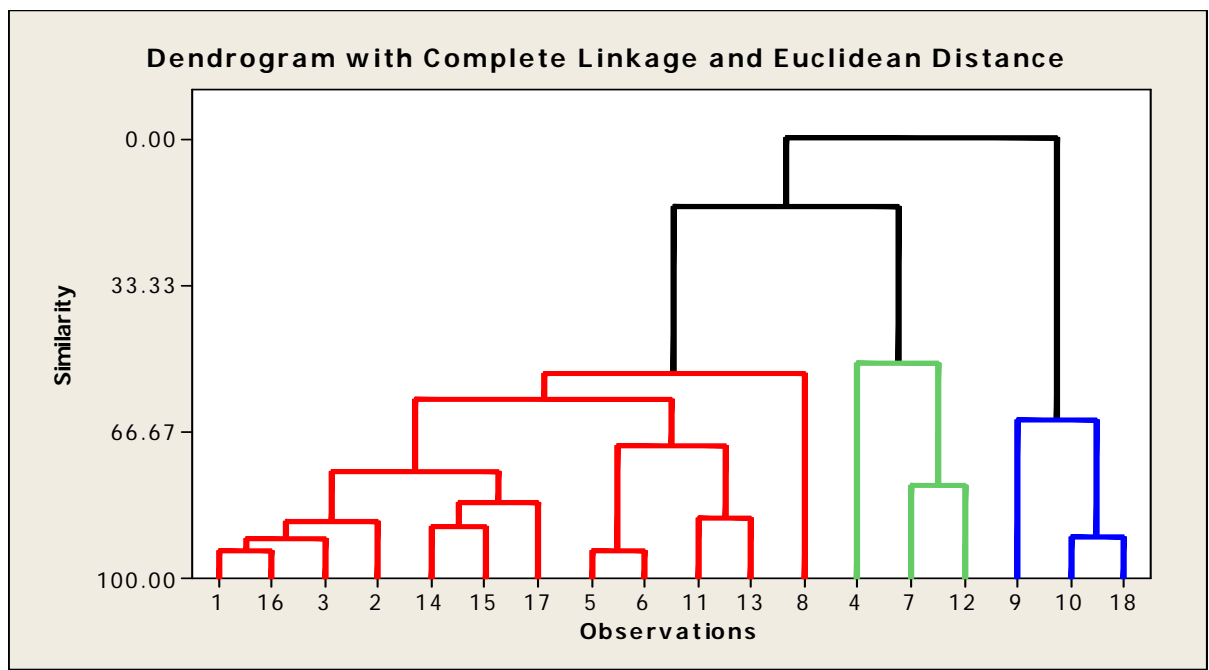

Figure 1: The Country Group Clusters, presented in Dendrogram form

- Twelve (12) countries were clustered in the red group, namely: Australia, United Kingdom, France, Canada, Sweden, Switzerland, USA, Ireland, Malaysia, Portugal, Spain and Norway. These countries are identified with high HDI and a strong majority of them are $1^{\text {st }}$ world countries.

- Three (3) countries were clustered in the green group, namely: India, New Zealand and Singapore. These countries offer consistent buyer-protection programs on purchases made online, and offer tax-free barter.

- Three (3) countries were clustered in the blue group: Philippines, Poland and Vietnam. Except for Poland, it is notable that both countries have developing economies and lower Human Development Indexes. Membership to auction sites is in between 4-5 years. 
From this initial information, for countries to experience higher ranking in Seller Levels due to Customer Satisfaction (consistent positive feedbacks are essential to increase consumer trust, as left by customers experiencing good service, fast shipping, efficient communication and accurate product description), it must acquire the attributes present in countries from cluster 1 or 2 .

Using cluster analysis, this process partially concluded behaviors present in higher ranking countries (as manifested by the first cluster) with respect to positive performance from the outcome factor. The entire process is summed up as a theory to be tested via cluster regression. The value of the R-Squared represents the influence of the dependent variable (outcome) with respect to the seven other variables observed. It utilized the comparison of the F-value and the f-critical to determine its significance.

\section{Theory Generation: Context Variables against Outcome Variables}

The behavior of the countries present in clusters one and two in terms of the ranking in the Network Readiness Index is relatively on the upper quarter of the listing, while they listed on the upper half in terms of Human Development Index and economic Level of Development. The study surmised the theory that,

"Countries that perform high in their Network Readiness Index with developed economies and high Human Development Indices tend to be very active online merchants with highly recommendable feedbacks."

Table 2: Cluster Centroids for the Context Variables

\begin{tabular}{|ccccc|}
\hline Variable & Cluster1 & Cluster2 & Cluster3 & Grand Centroid \\
\hline Network Readiness Index & 17.08 & 22.66 & 67.66 & 26.44 \\
\hline Human Development Index & 1.08 & 1.66 & 2.33 & 1.38 \\
\hline Level of Economical Development & 1.16 & 1.66 & 2.66 & 1.5 \\
\hline
\end{tabular}

Subjecting this theory to validation by statistical regression, we have this table:

Table 3: Regression Results for Context Variables

\begin{tabular}{|cccc|}
\hline Variable & R-Squared (\%) & F-Value & Remarks \\
\hline NRI & 20.1 & 4.03 & Significant \\
\hline HDI & 15.2 & 2.87 & Not Significant \\
\hline Level of Development & 13.1 & 2.41 & Not Significant \\
\hline
\end{tabular}

f-critical at 3.34, with unusual observations for Philippines and Portugal

The theory is then modified to reject variables that use the influence of HDI and Level of Development to the tested outcome, thus we come up with a modified theory:

"Countries that perform high in their Network Readiness Index with varied economies and Human Development Indices tend to be very active online merchants with highly recommendable feedbacks." 


\section{Theory Generation: Input Variables against Outcome Variables}

The cluster 1 and 2 factors for input variables indicated strong internet speeds, from 9.5-13 mbps. Language use is not a significant contributor to better seller attributes, but maintaining a good and lasting relationship with auction site administrators (at least 5 years) can provide sturdy benefits that may lure potential customers from global brand names. All country clusters offer international selling activities, and identified themselves with both ends of the barter as buyers and as sellers. Thus, we come up with another theory, stating:

"Online customers prefer to transact with site-loyal merchants equipped with strong internet connections, as long as communication can happen between both parties. Transactions usually happen virtually, as traders can establish in one country but provides goods and services overseas. These traders supplement the buying and selling practices in negotiating for good deals."

Table 4: Cluster Centroids for the Input Variables

\begin{tabular}{|ccccc|}
\hline Variable & Cluster1 & Cluster2 & Cluster3 & Grand Centroid \\
\hline Internet Speed & 13.03 & 9.56 & 6.92 & 11.43 \\
\hline Language Used & 1.58 & 1.00 & 1.33 & 1.44 \\
\hline Status of Traded Items & 1.19 & 1.02 & 1.12 & .15 \\
\hline Membership (months) & 63.03 & 99.79 & 57.04 & 68.5 \\
\hline Merchant Attributes & 1.60 & 1.55 & 1.49 & 1.57 \\
\hline
\end{tabular}

Subjecting this theory to validation by statistical regression, we have this table:

Table 5: Regression Results for Input Variables

\begin{tabular}{|cccc|}
\hline Variable & R-Squared (\%) & F-Value & Remarks \\
\hline Internet Speed & 9.5 & 1.6 & Not Significant \\
\hline Language Used & 15 & 2.82 & Not Significant \\
\hline Status of Traded Items & 18.3 & 3.59 & Significant \\
\hline Membership (months) & .4 & .07 & Not Significant \\
\hline Merchant Attributes & 37.4 & 9.54 & Significant \\
\hline
\end{tabular}

f-critical at 3.34, with unusual observations for Sweden, Norway, Portugal

Based on the table above, Internet speed, Language used and Membership terms are not the variables that strongly affect better online trading. Therefore, the theory is revised:

"Online customers prefer to transact with merchants who trade internationally and exhibit a buying and trading practice. These transactions happen even at variably low internet speed, even with longstanding (in terms of membership) merchants who use their host country's native language." 


\section{Theory Generation: Process Variables against Outcome Variables}

In process variables, the study looked at the number of transaction methods agreed by both parties, whether they tend to use bidding or just buy the item immediately. It also observed the delivery methods used by the sellers, as well as the payment facilities used to close the trade.

Since the trade area is basically known as a bidding site, Strong trade players often use this method to set their products up for sale. They also offer at least 2-3 ways to deliver the items with corresponding rates, as well as more payment options for the buyer to consider.

Theory: "Majority of the key players in e-bidding/e-auction sites provide at least 2-3 delivery methods and payment options to successfully complete the trade."

Table 6: Cluster Centroids for the Process Variables

\begin{tabular}{|ccccc|}
\hline Variable & Cluster1 & Cluster2 & Cluster3 & Grand Centroid \\
\hline Transaction Methods & 1.34 & 1.69 & 1.24 & 1.38 \\
\hline Delivery Options & 2.33 & 3.40 & 3.30 & 2.67 \\
\hline Payment Alternatives & 3.56 & 3.98 & 2.56 & 3.47 \\
\hline
\end{tabular}

Subjecting this theory to validation by statistical regression, we have this table:

Table 7: Regression Results for Process Variables

\begin{tabular}{|cccc|}
\hline Variable & R-Squared (\%) & F-Value & Remarks \\
\hline Transaction Methods & 3.2 & .52 & Not Significant \\
\hline Delivery Options & 2.5 & .4 & Not Significant \\
\hline Payment Alternatives & 3.1 & .52 & Not Significant \\
\hline
\end{tabular}

f-critical at 3.34, with unusual observations for Sweden and Portugal

However, the three identified variables didn't establish strong influence to improve online selling attributes. The new theory is stated as:

\section{"Key players in online trade use multiple transaction methods and con- tinue to operate as long as delivery and payment alternatives are avail- able, even if these options are limited."}

\section{Theory Generation: Output Variables against Outcome Variables}

The output variables focused on post-transaction characteristics, such as local taxing, warranty coverage, defective product exchange options and buyer protection. The study showed that almost all surveyed countries apply local taxes and provide product warranty. Product exchange is very limited to high performing clusters but majority of the merchants enforce the buyer protection policies governing transactions that happen online. The outcome variable summarized this theory: 
"For transactions to succeed, options for product exchange must be in place for Damaged on Arrival (DOA) with least preference in item taxation and warranty coverage. Use of the Buyer protection policies is highly recommended as an alternative to address disputes and buyer-preferred recourse to product exchanges/returns.

Table 8: Cluster Centroids for the Output Variables

\begin{tabular}{|ccccc|}
\hline Variable & Cluster1 & Cluster2 & Cluster3 & Grand Centroid \\
\hline Local Taxes & 1.87 & 1.83 & 2.0 & 1.89 \\
\hline Warranty Provisions & 1.91 & 1.63 & 1.98 & 1.87 \\
\hline Exchange Options & 1.40 & 1.49 & 1.64 & 1.45 \\
\hline Buyer Protection & 1.26 & 1.13 & 1.37 & 1.26 \\
\hline
\end{tabular}

Subjecting this theory to validation by statistical regression, we have this table:

Table 9: Regression Results for Output Variables

\begin{tabular}{|cccc|}
\hline Variable & R-Squared (\%) & F-Value & Remarks \\
\hline Local Taxes & 1.1 & .18 & Not Significant \\
\hline Warranty Provisions & 5.1 & .86 & Not Significant \\
\hline Exchange Options & 21.1 & 4.29 & Significant \\
\hline Buyer Protection & 2.0 & .32 & Not Significant \\
\hline
\end{tabular}

f-critical at 3.34, with unusual observations for Sweden and Norway

From the variables presented, only Exchange Options are strong indicators of good web merchant practice. The other three variables failed to create a stimulus as an indicator for the outcome factor. The new theory:

\begin{abstract}
"Buyers prefer sellers that offer exchange option for products that underwent Damaged on Arrival (DOA). The Buyers have minimal considerations regarding taxes, warranty provisions or buyer protection as long as they have the product in good condition upon arrival. They opt to have it exchanged when they find it defective".
\end{abstract}

\title{
Conclusions \& Recommendations
}

There are several reasons why a specific country excels successfully in online trading. Other factors not considered in study would include IT literacy and government support for such activities. The theories formulated from the findings of this survey may provide insights for lawmakers to consider in addressing the circumstances not covered in the e-commerce act of 2000. A reasonable policy program addressed to motivate online barter and trade that benefits both the govern- 
ment and key players in this generations' businessman are key objectives set by this study, along with information that can dispel overrated misconceptions on web-related fraud.

These recommendations are based on the validated theories from the Context, Input, Process and Output factors with respect to the positive buying experience indicated by summary of the feedback ranking.

1. The study found out a direct connection between the rise of buyer satisfaction and a country's worldwide rank in being 'wired'. It is then recommended for the government to look at the factors that the World Economic Forum (WEF) measures to increase webbased productivity in business. Specifically, the policy makers should look at how the environment for ICT caters to businesses and what are offered to increase market, politi$\mathrm{cal} /$ regulatory and infrastructure influences. They should also make efforts to provide and allow citizens to understand the readiness of the community's key stakeholders (individuals, businesses, and governments) to use ICT, and finally the usage of ICT amongst these stakeholders.

2. Since online customers prefer to transact with merchants who trade internationally, initiatives should be carried by the government to extend its online capability to the rest of the world by educating the traders of these selling options. Furthermore, a lot can be learned by individuals by experiencing the selling and buying practices and methods, at such, he can be opened to the options of hunting for the best supplier overseas with consideration to the risks involved in damaged goods, tariff and freight costs. The theory also found out that online communication happen even at variably low internet speeds, so consistency and reliability in the internet infrastructure should initially be addressed. Strong seller and buyer attributes are also manifested over time, it is recommended for merchants to strongly protect their online identities (membership) as their physical identities; a superior record of successful transactions is essential as this can represent as a basis for customers in the future. It is also recommended to learn the language of the targeted market since merchants who trade online prefer to use their host country's native language.

3. It is also recommended to allow banking and monetary institutions to provide payment alternatives and methods that will induce a cashless society, provided that the government ensures network security and robustness check in the national network lines. This should be implemented to prevent pilferage and phising (illegal retrieval of personal information). Along with this line is the suggestion to streamline parcel delivery methods in an efficient and effective service-oriented practice. The government basically manages the postal services in the country yet it is one of the least method to send purchased goods due to slow delivery, embezzlement of items, damage in transit and the lack of tracking mechanisms. Product delivery is one of the pillars in online trading, while this method is in disarray, seller will resort to private corporations that offer the contrary of the current vices of the government postal systems at a higher price, skyrocketing purchase costs. This will dampen the development of online based barter.

4. It is also strongly suggested that policies in product exchanges be strengthen as these are the preferred recourse methods identified by most buyers that are convenient in cases of DOAs. The Department of Trade and Industry can provide seminars and forum regarding how they, as a national office, help protect consumers regarding purchases within their jurisdiction, while also looking for ways and means to expand their scope by teaming up with similar offices from other countries. Packing quality in mailed merchandise should be improved (availability of bubble wrap and stryro-cushions options) and made cost efficient, along with automated electronic postage creation as practiced by the United 
Neri, Bangis, Budlong, Clado, Ebot, Fransisco, \& Ignacio

States Postal Services (USPS) and the United Postal Services (UPS), as well as FedEx and DHL couriers.

5. A copy of this study after its final revision will be furnished to the Director of the Commission on Information and Communications Technology (CICT) head office. The said output will outline the highlights of cluster 1 countries and the validated theories presented to provide a venue and suggest the testing of the theories in actual practice or through a series of end-user consultation.

6. Further studies on the behavior of outlier countries for the possibility of the formulation of new theories.

\section{References}

AHN Media Corporation. (2006-2009). The Philippines reaffirms status as "text messaging capital of the world. Way odd website. Retrieved July 24, 2011, from http://www.wayodd.com/the-philippinesreaffirms-status-as-text-messaging-capital-of-the-world/v/8783/

Chan \& Robles. (1998-2006). Chan Robles Online Law Office. Retrieved July 27, 2011, from E-commerce law (RA 8792): http://www.chanrobles.com/republicactno8792.htm

Clepper, I. (1996, December 16). Contractor helps buyers recognize scams, scare tactics, overpricing. Air Conditioning, Heating \& Refrigeration News. Available from http://www.highbeam.com/doc/1G118961004.html

Coll, J., Dell Vecchio, R., Metzer, C., Scalise, E., Arrechederra, H., \& Fariña, M. D. (2004). Share, collaborate, create virtual conferences. Issues in Informing Science and Information Technology, 1, 393-405.

Dutta, S., \& Mia, I. (2011). The global information technology report 2010-2011 World Economic Forum. Retrieved November 22, 2011, from http://www3.weforum.org/docs/WEF_GITR_Report_2011.pdf

Ferbar, L. (2004). How Much Can We Spare with E-business: Examining the Effects in Supply Chain Management. Issues in Informing Science and Information Technology, 1, 141-155.

Harland, C. M. (1996). Supply chain management, purchasing and supply management, logistics, vertical integration, materials management and supply chain dynamics. UK: Blackwell.

Johnson, R. A., \& Wichern, D. W. (1992). Applied multivariate statistical analysis. Prentice Hall.

Jøsang, A. et al. (2007). Security usability principles for vulnerability analysis and risk assessment. Proceedings of the Annual Computer Security Applications Conference 2007 (ACSAC'07). Retrieved March 6, 2012 from http://www.unik.no/people/josang/papers/JAGAM2007-ACSAC.pdf

Kantor, M., \& Burrows, J. (1996) Electronic Data Interchange (EDI). National Institute of Standards and Technology. Retrieved 2008-05-13.

Kluge, S., \& Riley, L. (2008). Teaching in virtual worlds: Opportunities and challenges. Issues in Informing Science and Information Technology, 5, 127-135.

Gurevych, V. (2007). OsCommerce webmaster's guide to selling online: Increase your sales and profits with experts tips on SEO, marketing, design, selling strategies etc. Birmingham.

Padua, R. N. (2007). Graduate education policy framework for developing countries. Liceo Jounal for Higher Education, Liceo Press. Available online at http://ejournals.ph/index.php?journal=LJHER

Richardson, S. (2008) CSI computer crime and security survey . Retrived February 18, 2012, from http://i.cmpnet.com/v2.gocsi.com/pdf/CSIsurvey2008.pdf

Sicilia, M. A. (2005). Teaching e-commerce personalization technology: The need for a comprehensive view. Journal of Information Technology Education, 4, 85-96. Retrieved from http://www.jite.org/documents/Vol4/v4p085-096Siciia.pdf 
Tkacz, E., \& Kapczynski, A. (2009). Internet - Technical development and applications. Springer. Retrieved 2011-03-28 from http://books.google.com/books?id=a9_NJIBC87gC\&dq.

Turban, E., McKay, J., Marshall, P., Lee, J., \& Vielhand, D. (2008). Electronic commerce 2008: A managerial perspective. London: Pearson Education Ltd.

Tyron, R. (1939) Cluster analysis. New York: McGraw-Hill.

Wood, L. (2010, August 23). Research and Markets: Philippines - Telecoms, Mobile and Broadband. Business Wire News. Retrieved July 25, 2011, from http://www.businesswire.com/news/home/20100823005660/en/Research-Markets-Philippines--Telecoms-Mobile-Broadband

\section{Biographies}

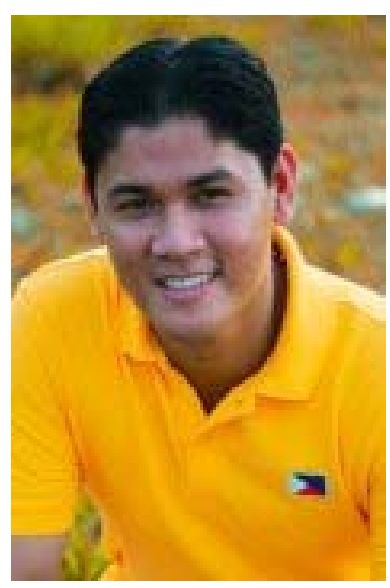

Jake Neri III continues his passion as a freelance photographer, getting huge discounts againts local retailers through online shopping. On several occassions, he has imported hard-to-find electronics and gadget lovers for a good haul. He has been a victim of fraudalent transactions over the course of time, but he credits this as part of the eternal learning proccess as he continues to advocate for strong ecommerce policies to protect buyer and seller interests. He also spares time in providing hands on training in starting up web-based selling using social networking and direct selling. He recently lost all of his cats. He currently nurses a small pooch before taking a plunge.

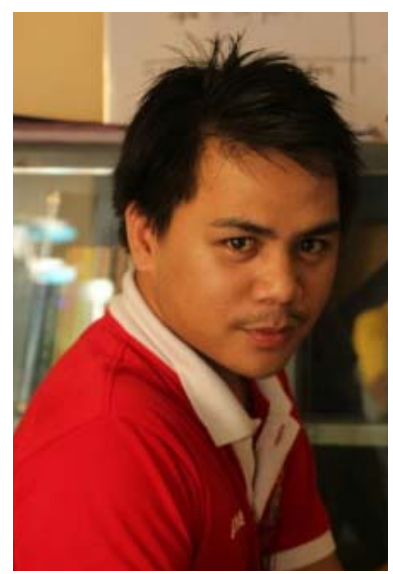

Arnel Bangis is one of the online sellers that exerts a lot of effort reverting to the old ways, where after completing a transaction, still prefers to meet the customer in real form. He ventures into the social network to keep abreast of the trends and selling opportunities. 


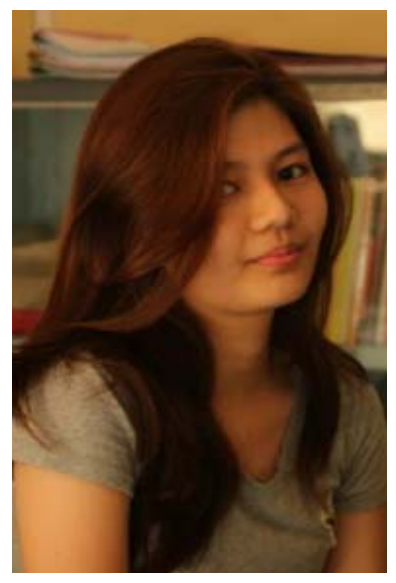

Theresa Budlong has kept her interests subtle until she finally finishes a task she considers of great important to change her life. A home buddy, she spends most of her time in a laid back life. She believes in pre-selling as a collective effort in the success of online transaction. She started as a reseller into the online trade before venturing into academic research.

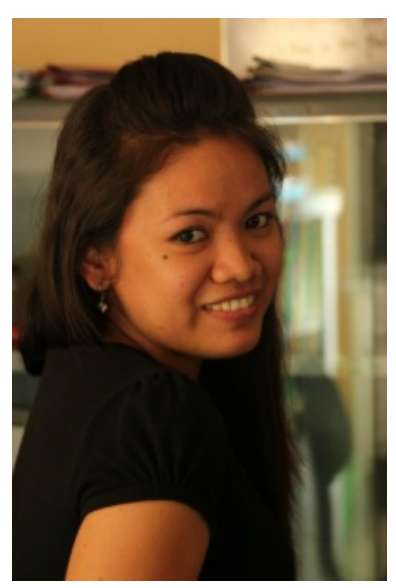

Jade Clado is a sublime woman, living life to the fullest. Aside from being the presiding officer of the Peer Counselor Association in her college years, she maintains close ties with her friends in the organization. She is fond of writing poems and hopes to grow the gut to publish them online in her web blog. She is on the process of putting up her own business in the future.

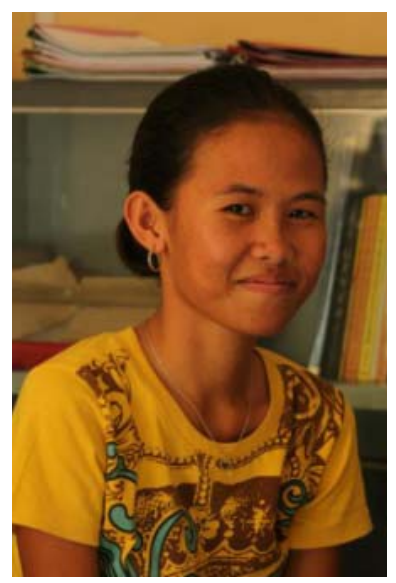

Irish Christine Ebot loves to join amateur singing contests. Her singing passion led her to try selective music purchases online after amassing albums of the artists of her prefernces. She believes that this passion need not be expensive while she spends most of her time socializing with her singing group, a church-based ensemble. 


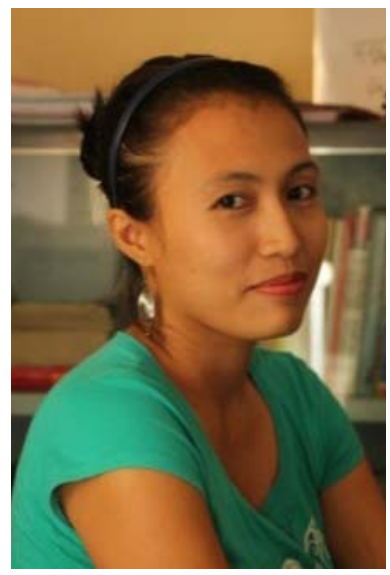

Analy Francisco likes to read novel books as a way of entering training herself. Aside from amassing a huge collection as a bookworm, she is also into collecting perfumes with reference to its delicate/phenomenal bottle designs and its influence to biased scent. She displays a wide variety in a pedestal, using online commerce as a resource to secure great deals in the future. She socializes with her friends, especially those who has affinity for cats.

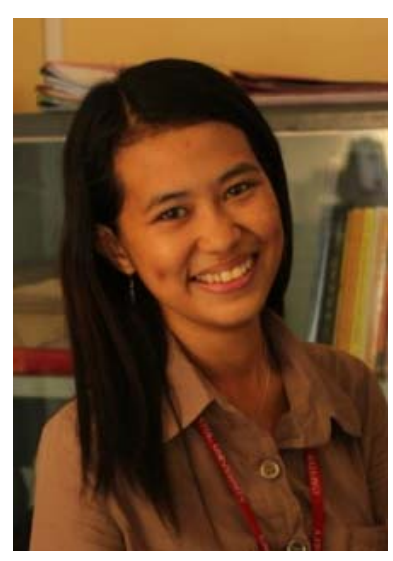

Minstrel Ignacio loves watching movies in her spare time. She also loves browsing/surfing in the internet for online deals and rummages. She is adventure-driven, loves to travel and an explorer of nature. She plans to go full time in online selling in the near future. 